Research Article

\title{
Flexural Behaviour of Unbonded Posttensioned Concrete Beam Strengthened with Aluminium Alloy Plates
}

\author{
Hong Chang ${ }^{1}{ }^{1}$ and Wei Zhou (D) $^{1,2,3}$ \\ ${ }^{1}$ School of Civil Engineering, Harbin Institute of Technology, Harbin, China \\ ${ }^{2}$ Key Lab of Structures Dynamic Behavior and Control, Ministry of Education, Harbin Institute of Technology, Harbin, China \\ ${ }^{3}$ Key Lab of Smart Prevention and Mitigation of Civil Engineering Disaster, Ministry of Industry and Information Technology, \\ Harbin Institute of Technology, Harbin, China \\ Correspondence should be addressed to Wei Zhou; zhouwei-hit@163.com
}

Received 21 November 2019; Revised 1 March 2020; Accepted 6 March 2020; Published 6 April 2020

Academic Editor: Jan Vorel

Copyright (c) 2020 Hong Chang and Wei Zhou. This is an open access article distributed under the Creative Commons Attribution License, which permits unrestricted use, distribution, and reproduction in any medium, provided the original work is properly cited.

\begin{abstract}
Owing to their high corrosion resistance, aluminium alloy (AA) plates bonded with magnesium phosphate cement (MPC) are considered as a viable candidate for reinforcing inshore infrastructures that are subject to severe environmental conditions and vapor atmospheres. Therefore, the aim of this study is the evaluation of the flexural behaviour of simple beams that are strengthened using this technique. Six unbonded posttensioned concrete (UPC) beams with different reinforcement ratios are damaged by static loads and then repaired and strengthened using AA plates. The failures under two-point loading are then investigated. Thereafter, a simplified method is proposed for the evaluation of the flexural strength of a UPC beam strengthened by an AA plate with MPC. The flexural strengths of the six specimens increase by an average of $14 \%$, and the displacement ductility factor decreases by an average of $34.14 \%$. Moreover, the increase and decrease ratios are proportional and inversely proportional to the comprehensive reinforcement index, respectively. The influences of the three main factors on the flexural strength of the AA plate are determined: the increase in the stress of the unbonded tendons, stress at the midspan and slippage at the ends of the AA plate, and increase ratio of the flexural strength. It shows that the AA plates bonded with MPC can be used successfully in concrete strengthening.
\end{abstract}

\section{Introduction}

Concrete structures are generally subject to significant external stimuli such as shock, vibration, and overload, which result in local damages to buildings during flexural or shearing processes. A common countermeasure involves the external bonding of these concrete structures with composite materials, thin steel plates, or other reinforcements.

Numerous experiments and analyses have verified the effectiveness of thin steel plates and fibre-reinforced polymer (FRP) sheets in the mechanical strengthening of concrete structures. Consequently, reinforcements using bonded thin steel plates and FRP sheets have been extensively implemented in various infrastructures [1-5]. However, given that steel is susceptible to corrosion in wet or vapor atmospheres, the bonding strengths at the interfaces of steel plates and concrete may be degraded, thus weakening the strengthening effect. Compared with steel and FRPs, the aluminium alloy (AA) plate is preferable due to its lower weight than steel, with a similar tensile strength and ductility, in addition to a higher ductility than FRP, similar flexural strength, and comparable corrosion resistance. Therefore, the AA plate is considered as an excellent material for external bonding and strengthening. Moreover, it is limited by the use of epoxy as the adhesive, which is disadvantageous due to its low temperature and aging resistance, in addition to its pungent odour and toxicity. Hence, magnesium phosphate cement is preferable as a potential replacement of epoxy as the main adhesive for structural strengthening in the high-temperature 
environment due to its high strength, low shrinkage, hightemperature resistance, and nontoxicity.

Externally bonded AA plates have been used for the strengthening of the flexural and shear capacities of reinforced concrete (RC) beams, which exhibit a higher ductility than those strengthened with externally bonded FRP sheets [6]. Moreover, they are underutilized due to debonding, as reported in studies on the application of externally bonded steel plates and FRP sheets. Accordingly, a near-surface mounted reinforcement technique was proposed, which is advantageous due to its effective enhancement of the stiffness and ultimate flexural capacity of beams, in addition to the utilization of the strength of the AA plate. However, it is disadvantageous due to the significantly lower ductility of beams when compared with those reinforced using the external bonding technique [7]. The relationship between the bonding and slippage of AA plates and concrete can be determined based on the FRP theory [8]. Three failure modes of the NSM AA plate reinforced concrete (RC) beams have been reported, which include concrete interfacial debonding, bending shear destruction, and AA plate destruction [9]. In a previous study, the bonding performance between an AA plate and concrete was investigated by considering the effects of the bond length and width of the AA plate [10]. Moreover, AA plates have been employed for the external strengthening of RC beams under shear, and the shear strength was approximately predicted by codes developed for the FRP of the ACI440, FIB14, TR55, and SMCFT standards [11]. A finite element model was developed and verified for the investigation of the behaviour and prediction of the performance of RC beams externally strengthened under shear using AA plates [12]. In previous studies, epoxy was used as the adhesive for the bonding of AA plates, and no studies have been conducted on the inorganic adhesive, with reference to the literature. In particular, MPC has been verified as a potential alternative adhesive for concrete structural strengthening under severe environmental conditions [13, 14].

In this study, an AA plate bonded with MPC was employed for the strengthening of (unbonded posttensioned concrete) UPC beams, followed by complete failure under static loads. The main focus was on the cracking, deflection, ultimate flexural strength, and ductility of the strengthened beams. The ultimate flexural strengths of the UPC beams strengthened with AA plates were then calculated based on the experimental results and a theoretical analysis.

\section{Materials and Methods}

2.1. Materials. A total of six damaged UPC beams were repaired and strengthened, and their dimensions, reinforcement details, and cross-section details are shown in Figure 1. The unbonded tendon arrangement is shown in Figure 2. All these beams had the same length of $6000 \mathrm{~mm}$ and different reinforcement ratios. The mechanical properties of the non-prestressed reinforcement are shown in Table 1.

The reinforcement index of the non-prestressed reinforcements was $\beta_{\mathrm{s}}=f_{\mathrm{y}} A_{\mathrm{s}} / f_{\mathrm{c}} b h_{\mathrm{p}}$, that of the unbonded tendons was $\beta_{\mathrm{p}}=\sigma_{\mathrm{pe}} A_{\mathrm{p}} / f_{\mathrm{c}} b h_{\mathrm{p}}$, that of the AA plate was $\beta_{\mathrm{a}}=\sigma_{\mathrm{a}} A_{\mathrm{a}} / f_{\mathrm{c}} b h$, that of the compression reinforcement was $\beta_{\mathrm{s}}^{\prime}=f_{\mathrm{y}}^{\prime} A_{\mathrm{s}}^{\prime} / f_{\mathrm{c}} b h_{\mathrm{p}}$, and the compositive reinforcement index was $\beta_{0}=\beta_{\mathrm{s}}+\beta_{\mathrm{p}}+\beta_{\mathrm{a}}-\beta_{\mathrm{s}}^{\prime}$. Moreover, $b$ is the width of each UPC beam; $h_{\mathrm{s}}, h_{\mathrm{p}}$, and $h_{\mathrm{a}}$ are the distances between non-prestressed reinforcement, unbonded prestressed tendons, AA plate, and the edge of the compression zone of the beam, respectively, and $f_{\mathrm{y}}, \sigma_{\mathrm{pe}}, \sigma_{\mathrm{a}}$, and $f_{\mathrm{y}}^{\prime}$ are the yield strengths of the non-prestressed reinforcement, unbonded prestressed tendons, AA plate, and compression reinforcement, respectively.

All six UPC beams were damaged by static loads, followed by the crushing of the concrete in the compression zone. All the damaged beams exhibited relatively small residual deformation, and most of the cracks were closured. Table 2 presents the results of the first failures of the six beams.

2.2. Reinforcement of Test Beams. The damaged concrete in the compression zone of the beams was replaced with grouting material, followed by the bonding of the AA plates (width of $20 \mathrm{~mm}$ wide and thickness of $3 \mathrm{~mm}$ ) to the bottom of the beam with MPC. The resistance moment diagram of the strengthened beam was obtained to determine the section with the full utilization of strength, and its distance to the end of the AA plate was set greater than or equal to the minimum extension length $l_{\text {ap }}$, as determined by the following equation:

$$
l_{a p} \geq \frac{f_{a} t_{a}}{f_{b d}}+200,
$$

where $f_{a}$ is the tensile strength of the AA plate; $t_{a}$ is the thickness of the AA plate; and $f_{b d}$ is the bond strength between the AA plate and concrete interface, which was 35.8 $\mathrm{MPa}$ [15].

Based on equation (1), the bond length of the AA plate in the experiment was set as $4000 \mathrm{~mm}$ and the AA plates were bonded to the bottom of the beams.

Stainless steel bolts with diameters of $10 \mathrm{~mm}$ were anchored into predrilled holes with depths of $50 \mathrm{~mm}$ and diameters of $14 \mathrm{~mm}$ to bear the bonding shear force in the case of adhesive layer failure and to exert uniform pressure on the AA plate for the enhancement of the bonding. Moreover, they were set with spacings of $300 \mathrm{~mm}$ (see Figure 3), and the overall structure of the strengthened beam is shown in Figure 4.

2.3. Mechanical Properties of Materials. Grade C40 concrete was used to cast the UPC beams. In addition, P.O. 42.5 Portland cement and F Class fly ash were used as binders, with a water-binder ratio $(w / b)$ of 0.3 . Sand particles were used in Zone II as the fine aggregate, and crushed rocks were used as the coarse aggregate. The proportions of the concrete mix are shown in Table 3. The axially compressive strength of the concrete was $45 \mathrm{MPa}$, and the elastic modulus of the concrete was $33600 \mathrm{MPa}$. 


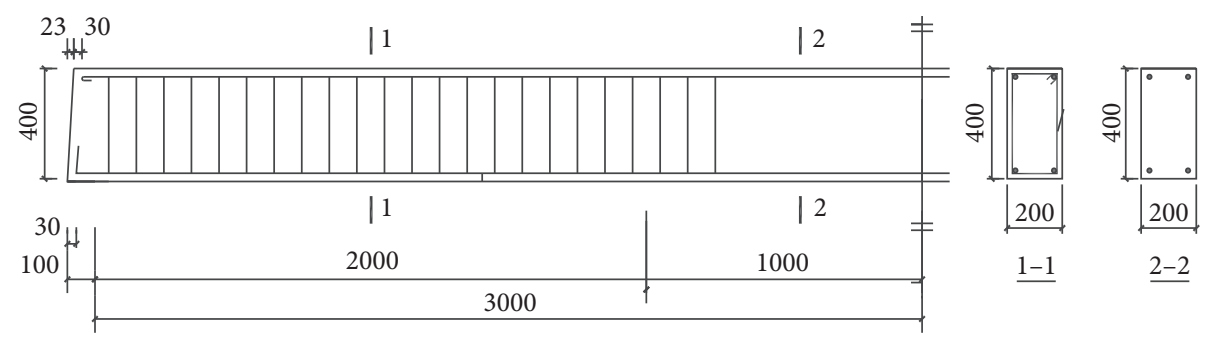

(a)

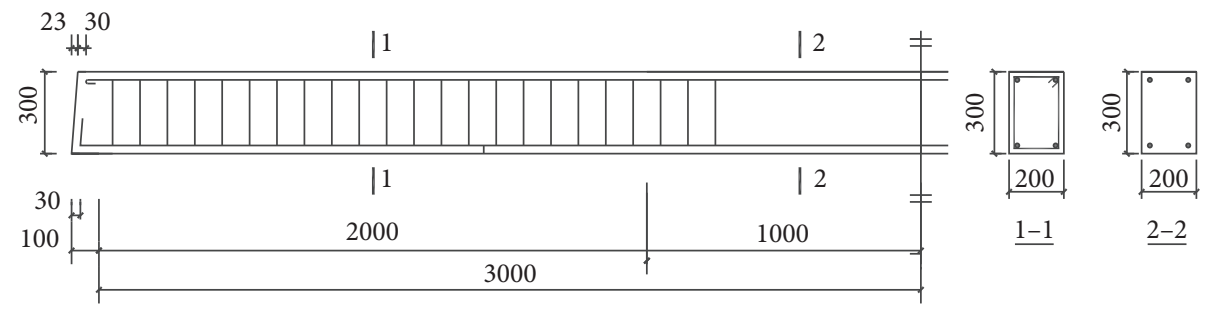

(b)

Figure 1: Design detail of test beams (mm). (a) AL beams. (b) AS beams.

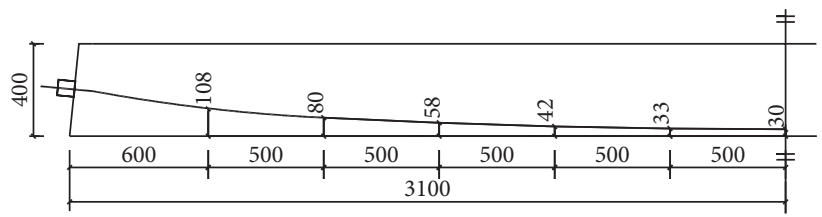

(a)

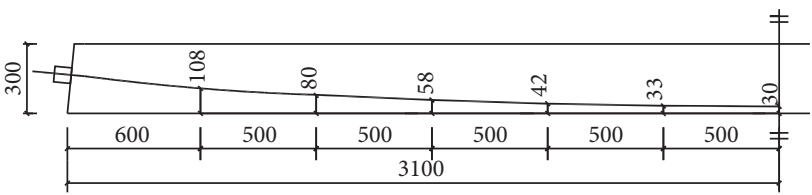

(b)

FIgURE 2: Arrangement of unbonded tendons (mm). (a) AL beams. (b) AS beams.

TABle 1: Parameters of test beams.

\begin{tabular}{lccccc}
\hline No. & Beam width $(\mathrm{mm})$ & Beam depth $(\mathrm{mm})$ & Diameter of reinforcements & $\beta_{0}$ & $\beta_{\mathrm{p}}$ \\
\hline AL1 & 200 & 400 & 12 & 0.128 & 0.090 \\
AL2 & 200 & 400 & 18 & 0.170 & 0.090 \\
AL3 & 200 & 400 & 25 & 0.027 \\
AS1 & 200 & 300 & 12 & 0.245 & 0.090 \\
AS2 & 200 & 300 & 18 & 0.159 & 0.107 \\
AS3 & 200 & 300 & 22 & 0.233 & 0.123 \\
\hline
\end{tabular}

TABLE 2: First failures of test beams.

\begin{tabular}{lccc}
\hline No. & Ultimate flexural capacity $\left(\mathrm{N} / \mathrm{mm}^{2}\right)$ & Height of crushed zone of concrete $(\mathrm{mm})$ & Ultimate deflection of midspan $(\mathrm{mm})$ \\
\hline AL1 & 180 & 50 & 139 \\
AL2 & 204 & 50 & 90 \\
AL3 & 200 & 40 & 67 \\
AS1 & 84 & 50 & 120 \\
AS2 & 104 & 50 & 106 \\
AS3 & 118 & 70 & 90 \\
\hline
\end{tabular}

Grade 1860 steel strands with diameters of $17.8 \mathrm{~mm}$ were used as unbonded tendons, with a tensile strength of $1915 \mathrm{MPa}$ and a nominal yield strength of $1732 \mathrm{MPa}$. Steel bars with diameters of $8 \mathrm{~mm}, 12 \mathrm{~mm}, 22 \mathrm{~mm}$, and $25 \mathrm{~mm}$ were used as the reinforcements, and their mechanical properties are shown in Table 4.
Tensile tests were conducted on the 5083 AA plates using an electronic universal test machine with $30 \mathrm{kN}$ (see Figure 5). The test results revealed that the AA plates exhibited a yield strength of $112 \mathrm{MPa}$, ultimate strength of $210 \mathrm{MPa}$, elastic modulus of $27800 \mathrm{MPa}$, and ultimate elongation of $27 \%$. 


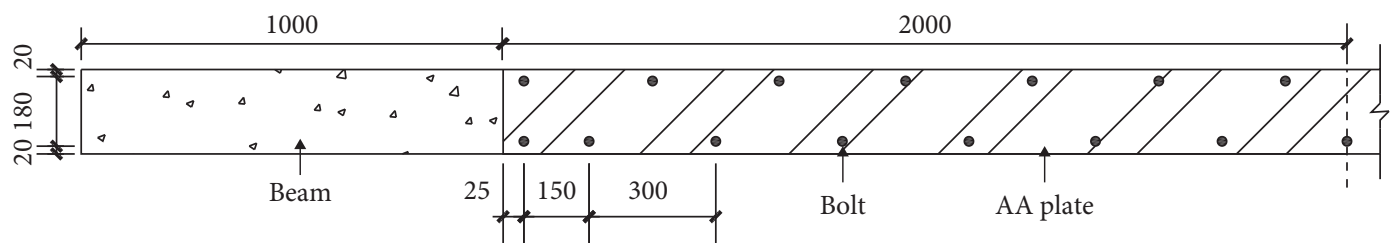

FIgure 3: Position of the AA plate and bolts (mm).

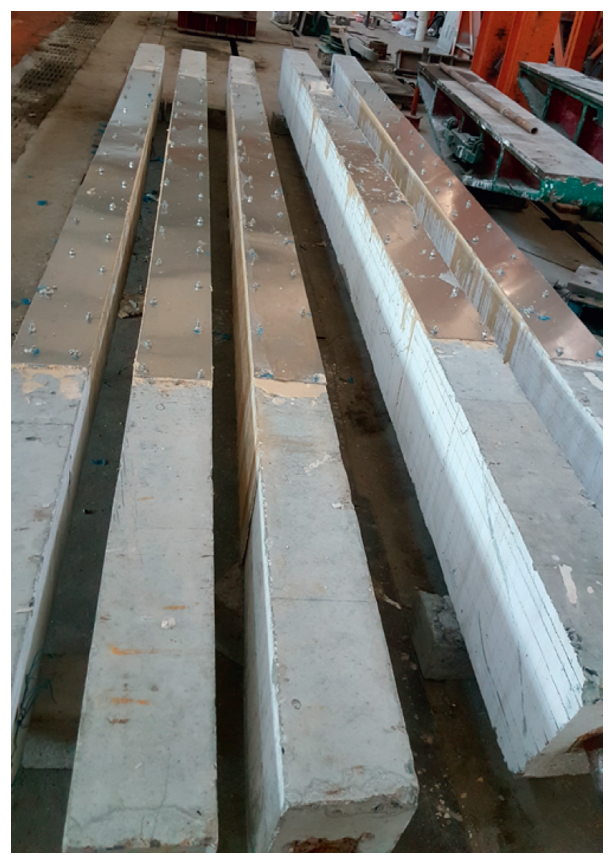

Figure 4: Overall appearance of strengthened beams.

TABle 3: Proportions of the concrete mix $\left(\mathrm{kg} / \mathrm{m}^{3}\right)$.

\begin{tabular}{|c|c|c|c|c|c|c|}
\hline Composition material & Binds & & Fine aggregate & Coarse aggregate & Water & Concrete admixture \\
\hline Type of material & P.O 42.5 Portland cement & F fly ash & Sand particles in zone II & Crushed rock & - & HF-3 \\
\hline Mixed quantity & 400 & 50 & 660 & 1085 & 170 & 15.3 \\
\hline Mixing ratio & 1 & & 1.47 & 2.41 & 0.38 & 0.034 \\
\hline
\end{tabular}

TABLE 4: Mechanical properties of non-prestressed reinforcements.

\begin{tabular}{lcc}
\hline Specification & Ultimate strength $(\mathrm{MPa})$ & Yield strength $(\mathrm{MPa})$ \\
\hline C8 & 575 & 402 \\
C12 & 575 & 402 \\
C22 & 629 & 405 \\
C25 & 672 & 489 \\
\hline
\end{tabular}

Figure 6 shows the stress-strain curve of AA plates, which was in accordance with Hooke's law and approximately linear before yielding and nonlinear after yielding. Figure 7 presents the relationship between the actual tensile test data and the fitted curve. Equations (2) and (3) express the fitted stressstrain relationship before and after yielding, and equation (3) yielded a correlation coefficient as high as 0.9966 :

$$
\begin{aligned}
\sigma_{a} & =27700 \varepsilon_{a}, \sigma_{a} \leq 112 \mathrm{MPa} \\
\sigma_{a} & =-40833 \varepsilon_{a} 4+31433 \varepsilon_{a} 3-9691 \varepsilon_{a} 2+1493 \varepsilon_{a}, 112 \mathrm{MPa} \\
& <\sigma_{a} \leq 210 \mathrm{MPa} .
\end{aligned}
$$

MPC was continuously improved, and it exhibited superior mechanical properties to that of Portland cement, which included a higher early strength, more rapid setting, smaller shrinkage, higher corrosion, and temperature resistance, and it improved bonding ability with concrete. In this study, MPC was prepared by mixing ammonium dihydrogen phosphate $\left(\mathrm{NH}_{4} \mathrm{H}_{2} \mathrm{PO}_{4}\right)$, magnesium oxide $(\mathrm{MgO})$, setting retarder (borax, $\mathrm{Na}_{2} \mathrm{~B}_{4} \mathrm{O}_{7} \cdot 10 \mathrm{H}_{2} \mathrm{O}$ ), and water 


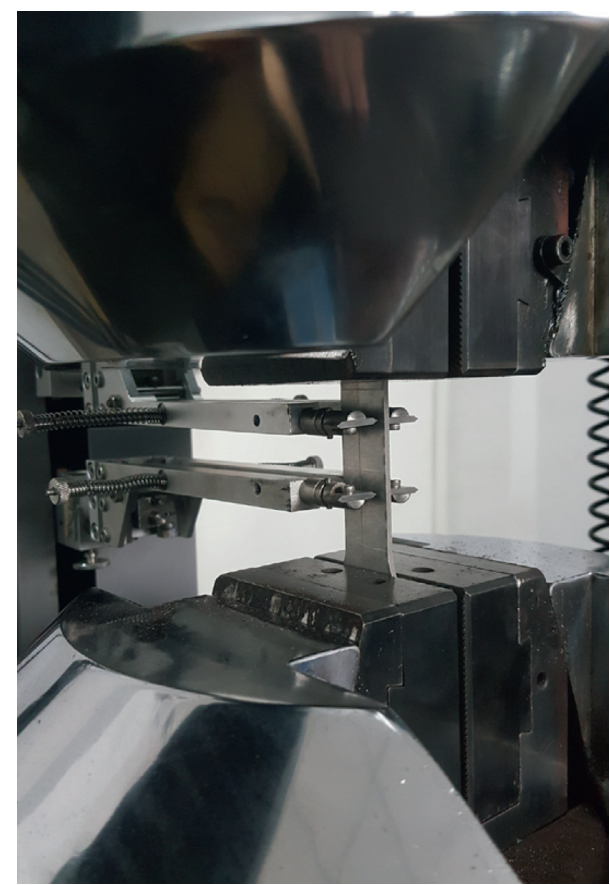

Figure 5: Tensile test of the AA plate.

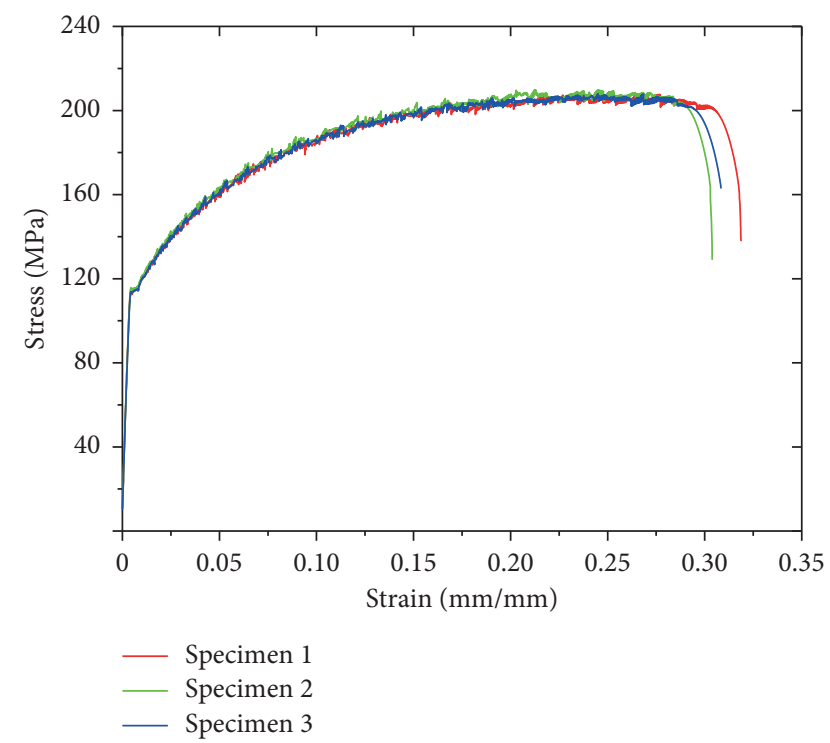

FIGURE 6: Stress-strain curve of AA plate.

$\left(\mathrm{H}_{2} \mathrm{O}\right)$ in a weight ratio of $26: 51: 4: 19$, respectively. The compressive and flexural strengths of the obtained MPC were $23.5 \mathrm{MPa}$ and $7.5 \mathrm{MPa}$, respectively.

2.4. Experimental Programme. Two-point loads were applied at one-third of the span of the simple supported beams (see Figure 8). A force sensor with $30 \mathrm{t}$ was installed under the end anchorage of the UPC beam for the measurement of the increase in the stress increment of the unbonded tendons. Three displacement sensors were placed under two loading points and the midspan of the beam for the measurement of

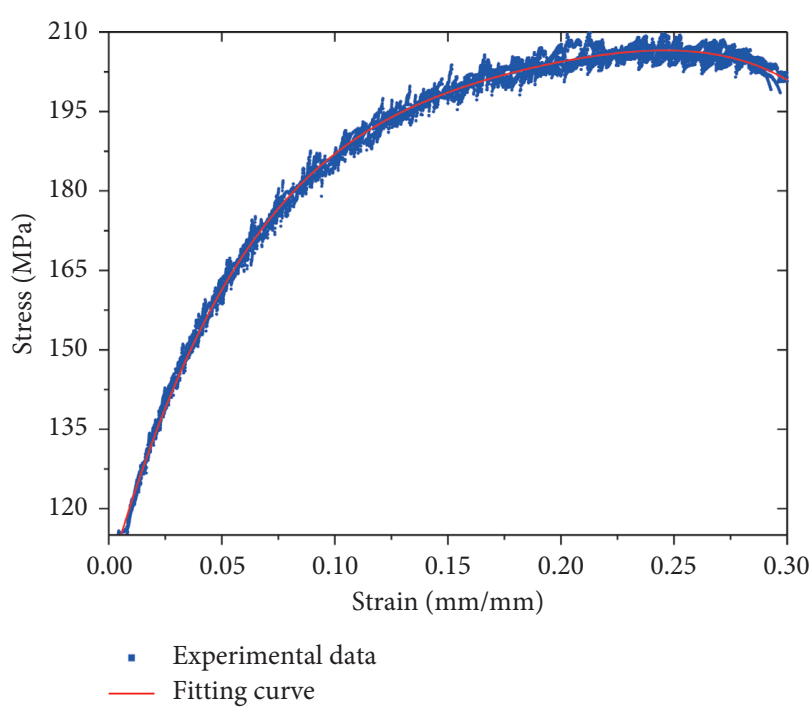

FIgURE 7: The relationship between the test result and the fitting result in the plasticity stage.

deflection, two sensors were installed at the end of the AA plate for the measurement of the relative slippage between the AA plate and the beam, and two additional sensors were installed above the supports for the measurement of the settlement of the supports. The beams numbered AL were subject to loads of $5 \mathrm{kN}$ at each level, whereas the beams numbered AS were subject to loads of $3 \mathrm{kN}$ at each level.

\section{Results}

3.1. Crack Development. The number of cracks in each beam increased gradually prior to the yielding of the non-prestressed reinforcement. Moreover, most of the cracks were generated during the initial failure, with their main distribution in the vicinity of two loading points and the bending section. After the yielding of the non-prestressed reinforcements, the widths and extension lengths of the cracks gradually increased. When the load approached the ultimate level, the widths and extension lengths of the cracks rapidly increased at the failure position where the cracks due to the initial failure were propagated at the highest rate. With the exception of several cracks in the bending section of the AL2 beam, the number of cracks in all the other beams decreased when compared with that at the initial failure. Therefore, it can be inferred that the AA plate exhibited an inhibitory effect on the number of cracks. The development and distribution of cracks are shown in Figure 9.

3.2. Beam Deflection. The ultimate deflection of each beam was less than that at the initial failure, which indicates that the deformation of the UPC beam was mitigated using this technique. In the experiment, strengthened beams were damaged and repaired, which impacted the beam stiffnesses; thus, the variations in stiffness of the strengthened beams were not significant, as shown in Figure 10.

As can be seen from Figure 10, the cross-sectional area and the comprehensive reinforcement index of the beams 


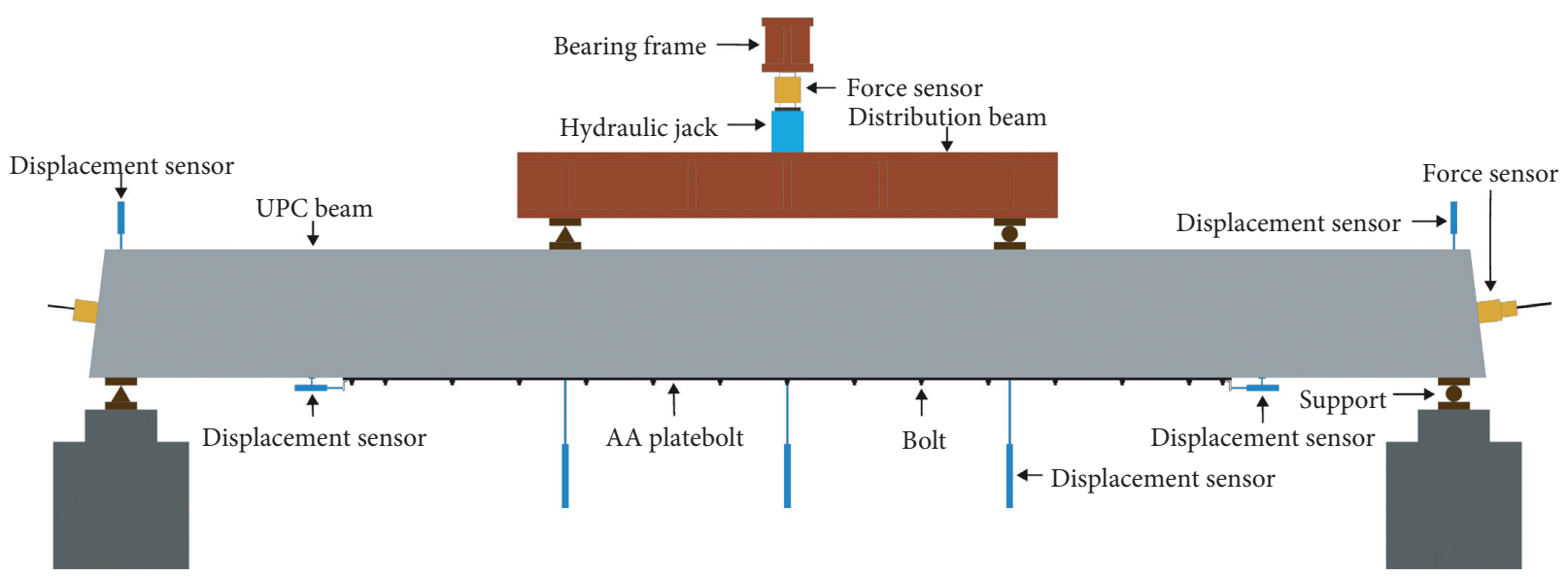

Figure 8: Design of the loading device for test beam.

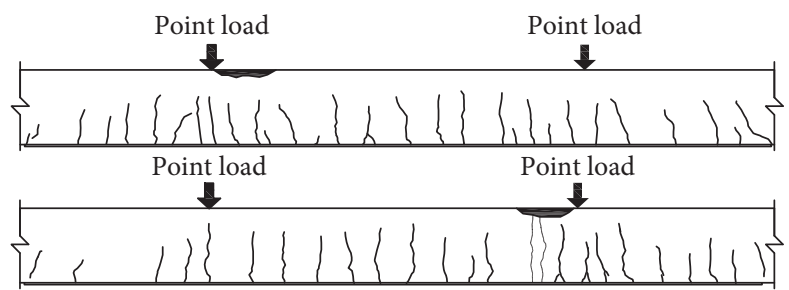

(a)

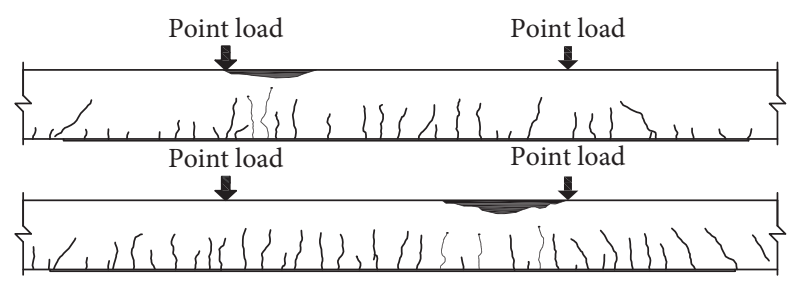

(c)

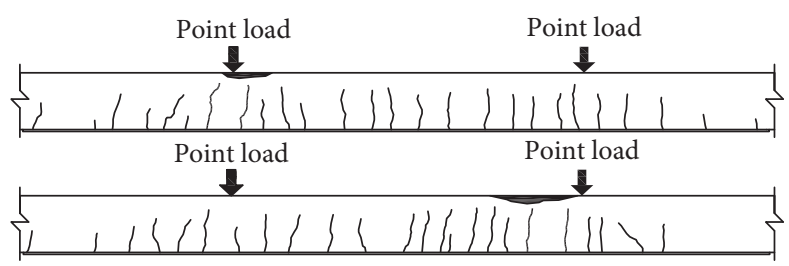

(e)

Figure 9: The crack distributions at failure.

are the two critical factors that influence the deflection. With the application of the same load, the deflection in the midspan of the AL beams with large cross-sectional areas was less than that of the AS beams with small cross-sectional areas. Moreover, the deflection of three beams with the same cross-sectional areas subject to the same load was inversely proportional to the comprehensive reinforcement index.

\subsection{Strain and Slippage of AA Plate}

3.3.1. Strain of AA Plate. The strains of the AA plate at two loading points and the midspan were systematically measured (see Figure 11).

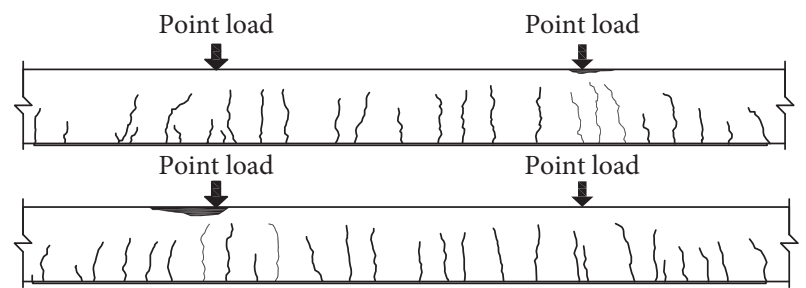

(b)

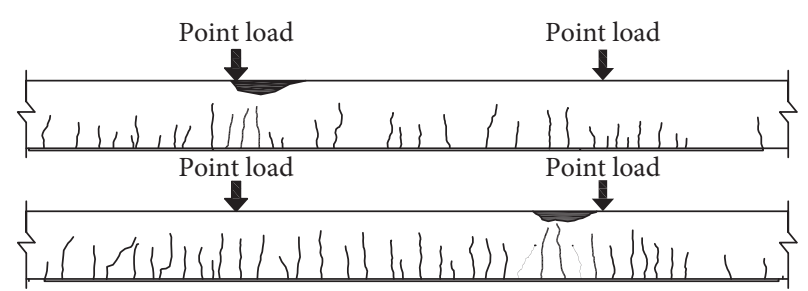

(d)

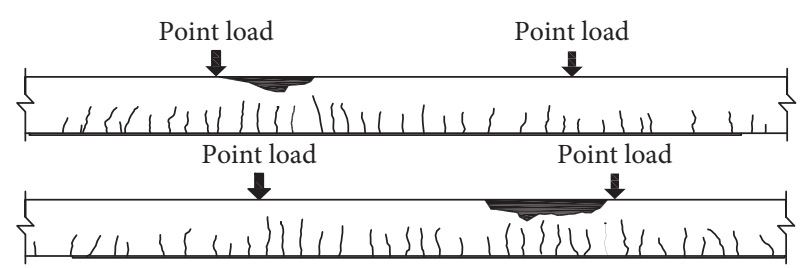

(f)

1, (b) AL2, (c) AL3, (d) AS1, (e) AS2, and (f) AS3.

As shown in Figure 11, the strains at three measuring points of each beam were similar at the initial stage of loading. When the non-prestressed reinforcement yielded, the strain rate at the midspan was accelerated. According to the stress-strain curve of the AA plate, the yield strain was determined as $4043 \times 10^{-4}$. When the strengthened beams were subject to failure, yielding occurred in the entire AA plates at the positions of the AL1 and AS1 beams, in addition to the midspan and loading point near the failure positions of the AL2 and AS3 beams. The AA plates of the AL3 beam approached yielding; however, no yielding was achieved. In the case of the AS2 beam, only the AA plate at the midspan yielded. This indicates that the tensile strength of the AA 


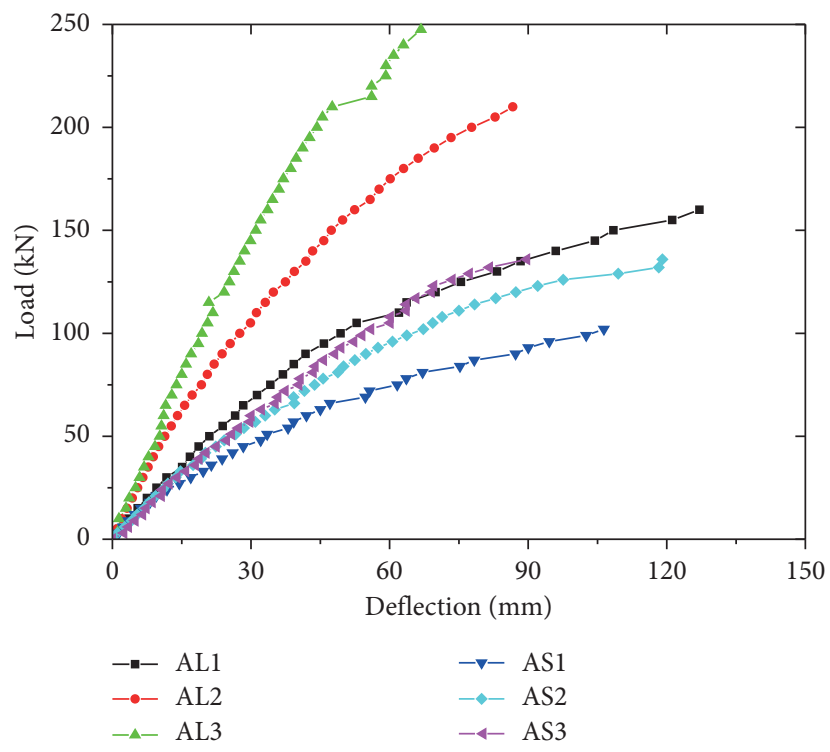

Figure 10: Load deflection of the midspan of the beams.

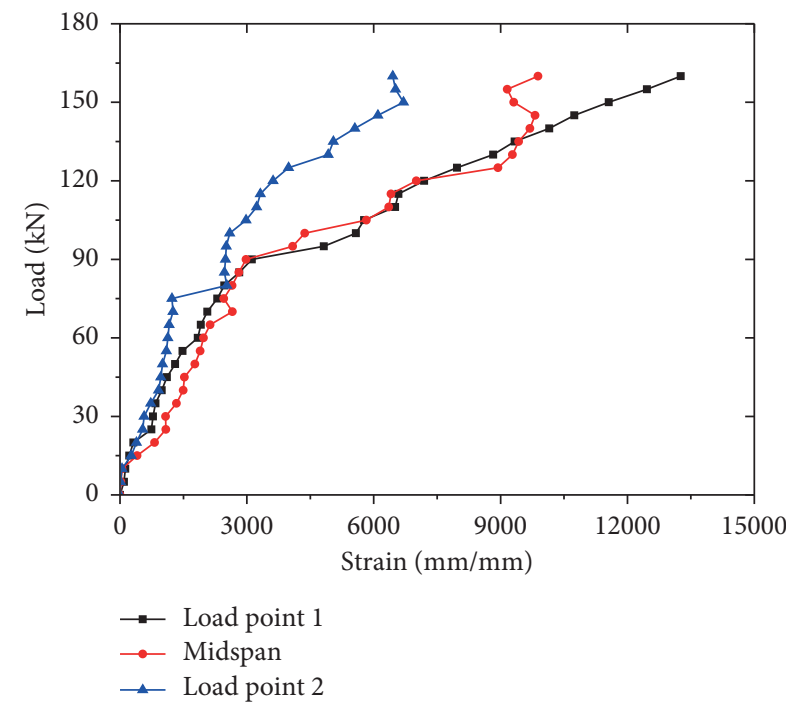

(a)

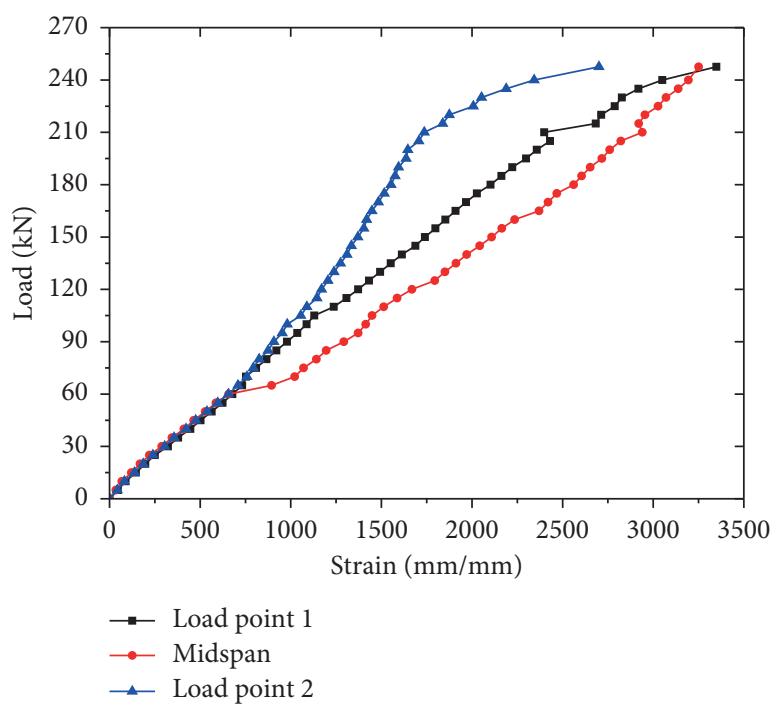

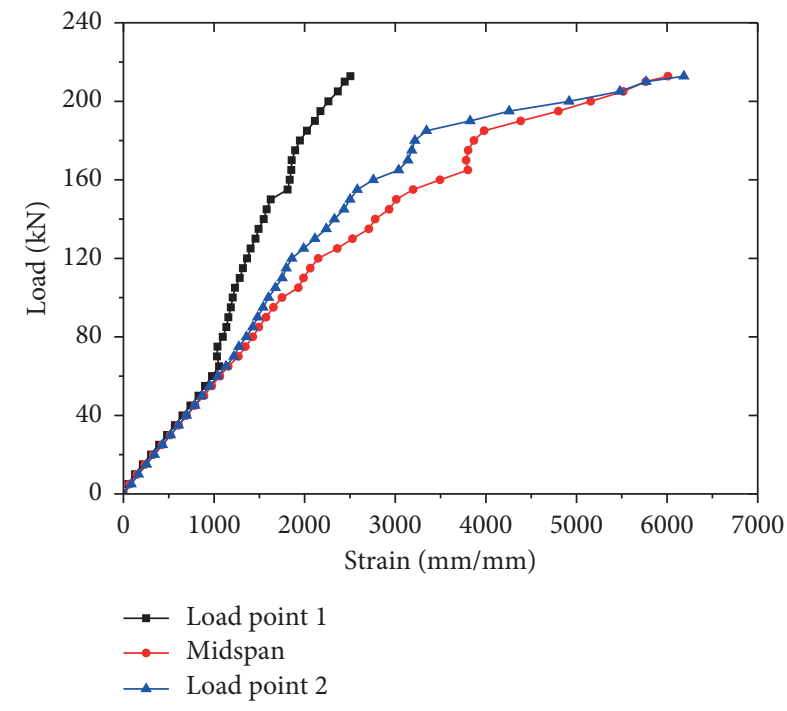

(b)

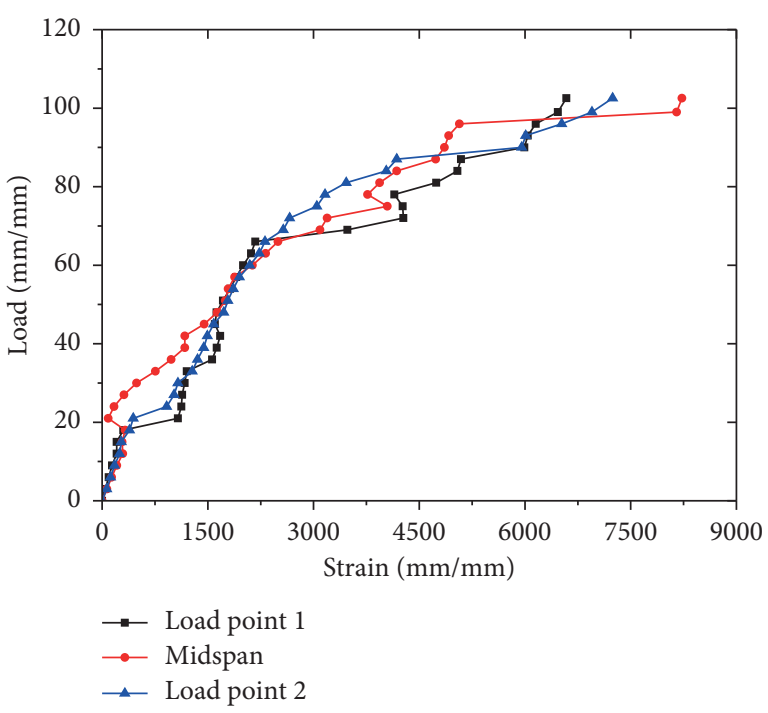

(d)

FIgURE 11: Continued. 


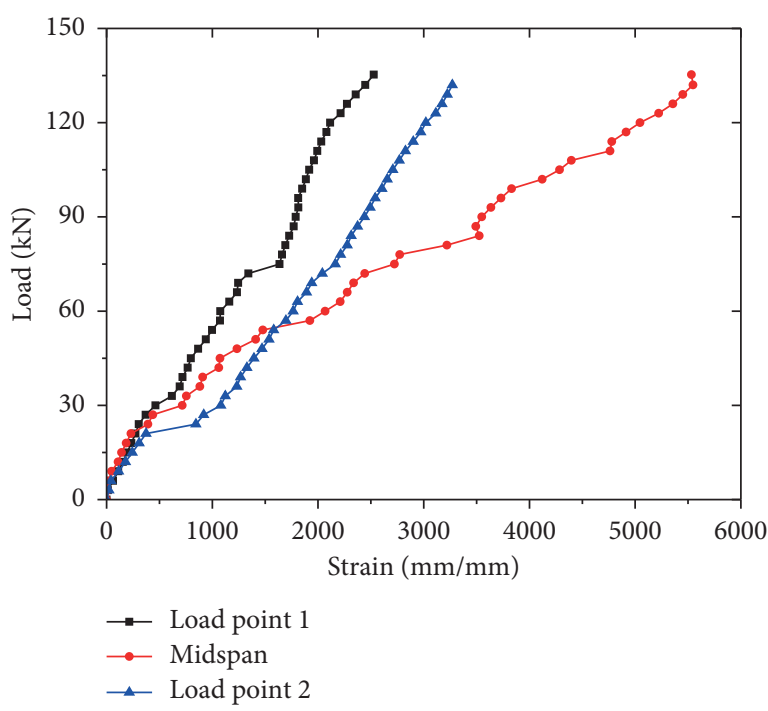

(e)

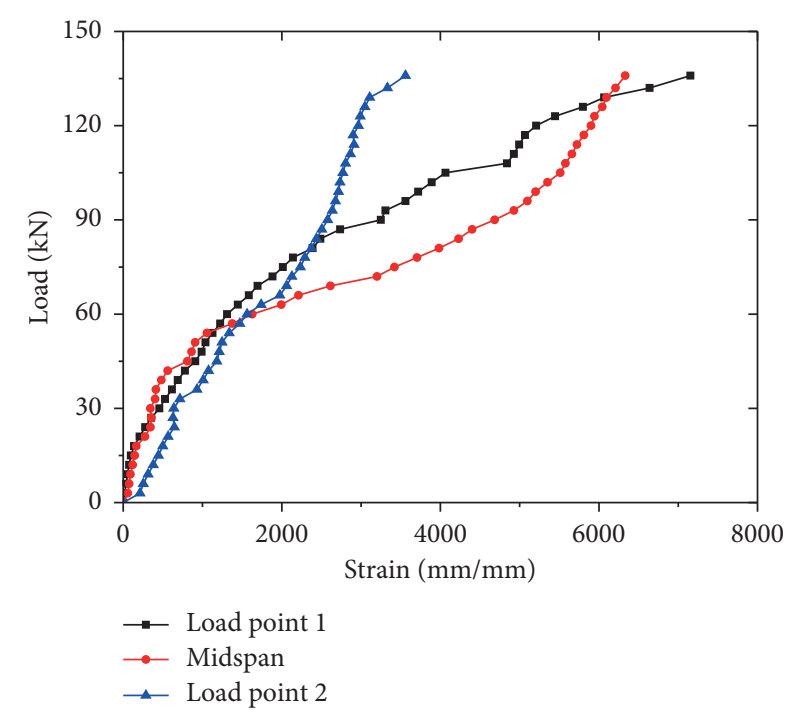

(f)

Figure 11: Load strain of the AA plate. (a) AL1, (b) AL2, (c) AL3, (d) AS1, (e) AS2, and (f) AS3.

plates in the bending section were fully utilized under the ultimate load, which indicates that the influence of the AA plate slippage on the flexural capacity with respect to strengthening was negligible.

3.3.2. Slippage of the AA Plate. The displacement sensors installed at the end of the AA plate measured the variation of the relative slippage between the AA plate and the beam during the loading process (see Figure 12).

The load-slip curves of each beam exhibited linear characteristics at the initial stage of loading, with a relatively moderate gradient. With the load increments, abrupt change emerged in the load interval of 30-60 kN, beyond which the curves were linear with a significantly larger gradient. The interface between the AA plate and the beam was subjected to complex forces under the joint action of MPC and bolts. However, no further research was implemented on the slippage at this interface, given that the slippage of the AA plate did not have an influence on the full utilization of the beam strength.

3.4. Stress of Unbonded Tendons. The relationships between the stress increments of the unbonded tendons and loads of each beam are shown in Figure 13.

The AL beams had large cross-sectional areas, the stress increased nonlinearly in accordance with the load, and the bending degree of the nonlinear curve was proportional to the comprehensive reinforcement index. The stress of the unbonded tendons increased gradually prior to crack propagation, rapidly after crack propagation, and more rapidly after yielding. In comparison, there was an approximately linear relationship between the load and stress increment in the AS beams with small cross-sectional areas, and the bending degree of the curve was proportional to the comprehensive reinforcement index.
Therefore, it can be concluded that the stress increment of unbonded tendons should be more sensitive to crack propagation and yielding in accordance with an increase in the cross-sectional area of the beam. Moreover, the sensitivity was found to be proportional to the comprehensive reinforcement index.

3.5. Failure Modes. The failure of the beams can be attributed to concrete crushing in the compression zone. Under the ultimate flexural strength, the non-prestressed reinforcements and AA plates yielded and the strengthened beams exhibited balanced failure. The AA plate was found to yield earlier based on a comparison of the strain between the AA plate and the non-prestressed reinforcement.

\section{Discussion}

4.1. Stress Increment of Unbonded Tendons. As demonstrated above, the slippage of the AA plate was negligible in the loading process, which indicates that it should be coordinated with the beam in the loading process. Hence, the internal force distribution within the cross section under the ultimate capacity can be illustrated as shown in Figure 14.

According to Figure 14, the equilibrium equation can be expressed as follows:

$$
f_{c} b x=f_{y} A_{s}+\left(\sigma_{p e}+\Delta \sigma_{p u}\right) A_{p}+\sigma_{a} A_{a}-f_{y}^{\prime} A_{s}^{\prime},
$$

where $f_{\mathrm{c}}$ is the compressive strength of the concrete; $x$ is the depth of the compression zone; $f_{y}$ is the tensile strength of the non-prestressed reinforcement; $\sigma_{p e}$ is the initial stress of the unbonded tendons; $\Delta \sigma_{p e}$ is the stress increment of the unbonded tendons; $\sigma_{a}$ is the tensile strength of the AA plates; $f_{\mathrm{y}}^{\prime}$ is the tensile strength of the compressive reinforcements; and $A_{s}, A_{p}, A_{\mathrm{a}}$, and $A_{s}^{\prime}$ are the areas of the nonprestressed reinforcement, unbonded tendons, AA plates, and compressive reinforcements, respectively. 


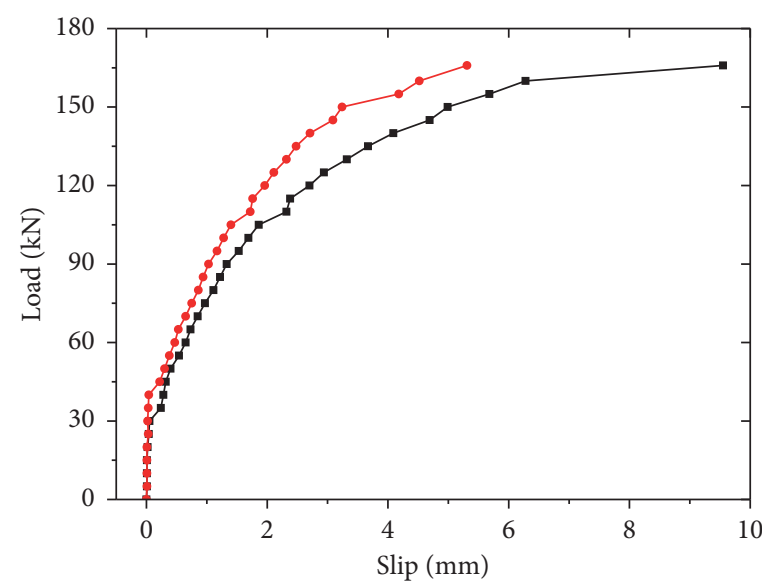

- Load point $\mathrm{A}$

$\rightarrow$ Load point $B$

(a)

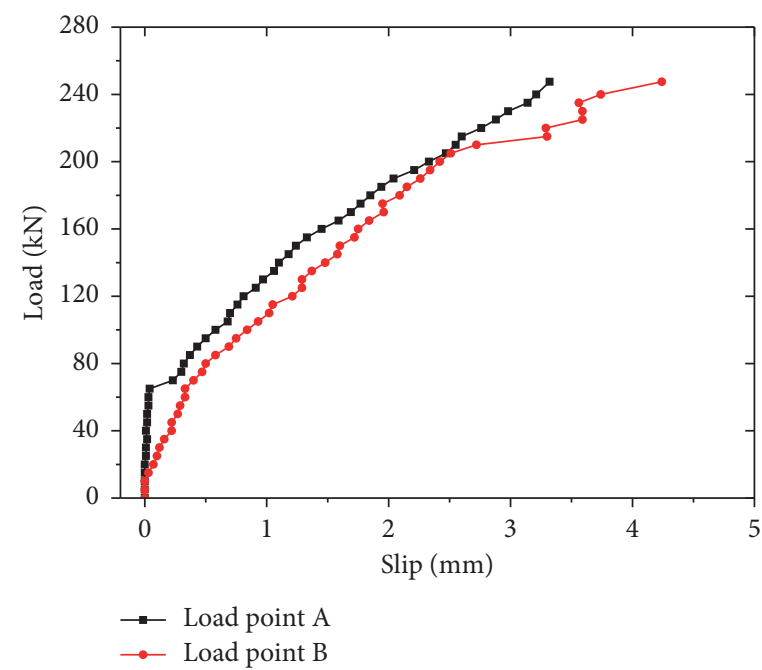

(c)

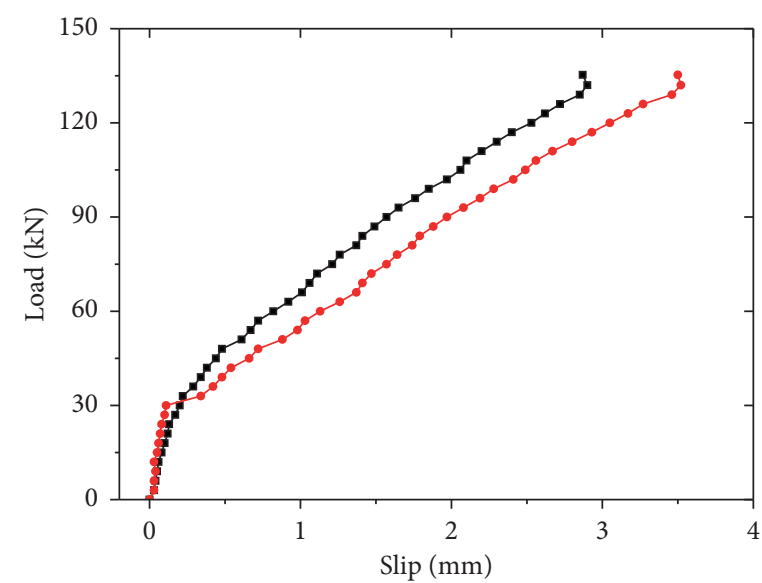

- Load point $\mathrm{A}$

$\rightarrow$ Load point $B$

(e)

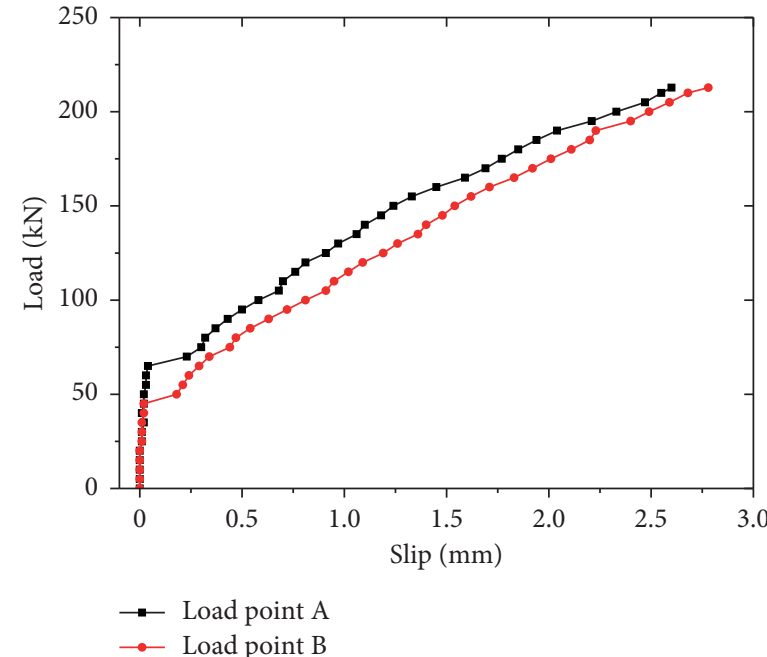

(b)

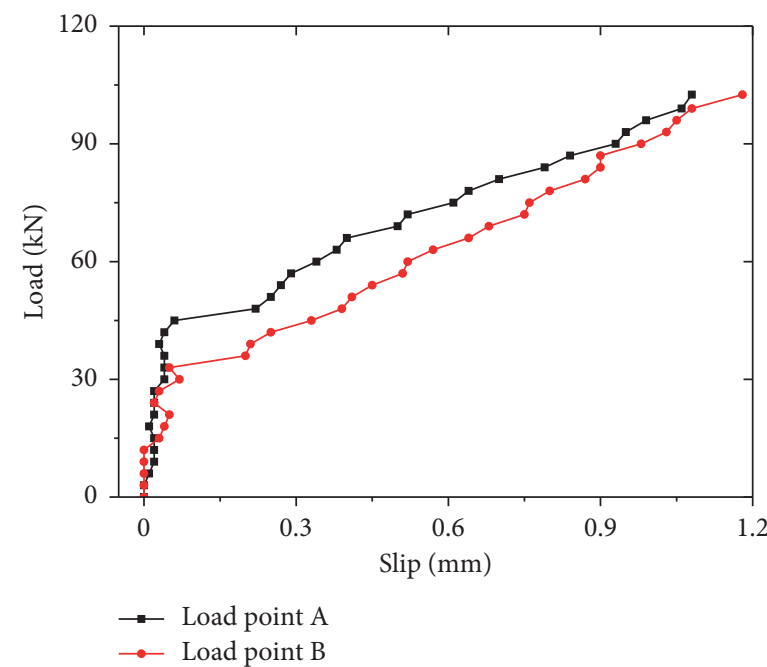

(d)

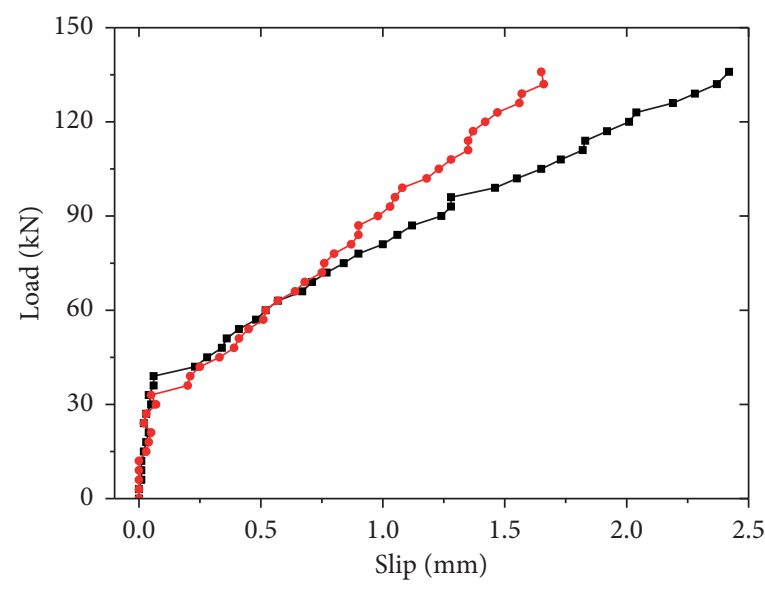

$\longrightarrow$ Load point A
$\rightarrow$ Load point B

(f)

Figure 12: The curves of load slip of the beams. (a) AL1, (b) AL2, (c) AL3, (d) AS1, (e) AS2, and (f) AS3. 


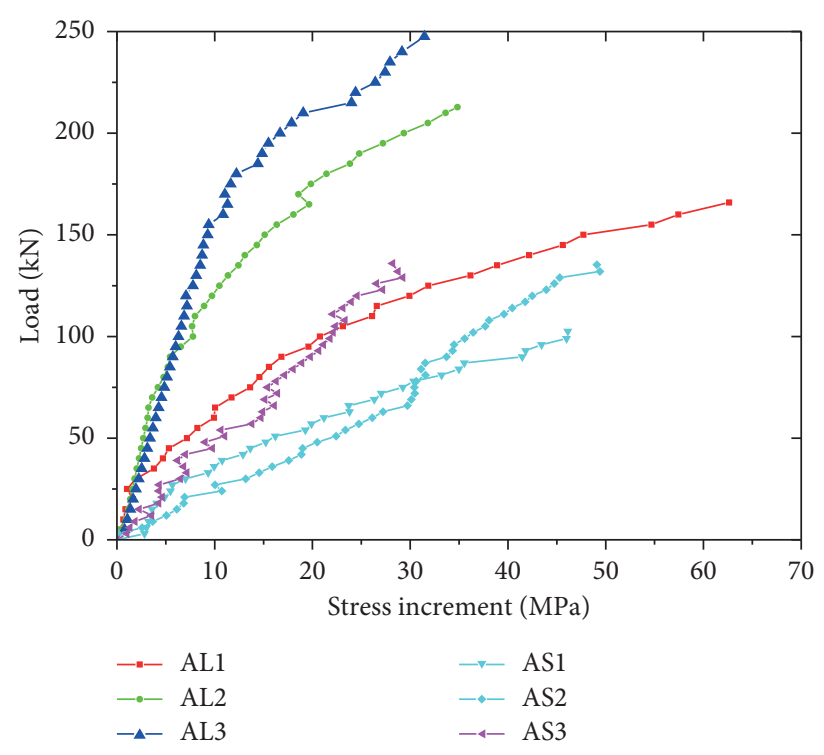

FIGURE 13: Load-stress increasement of unbonded tendons.

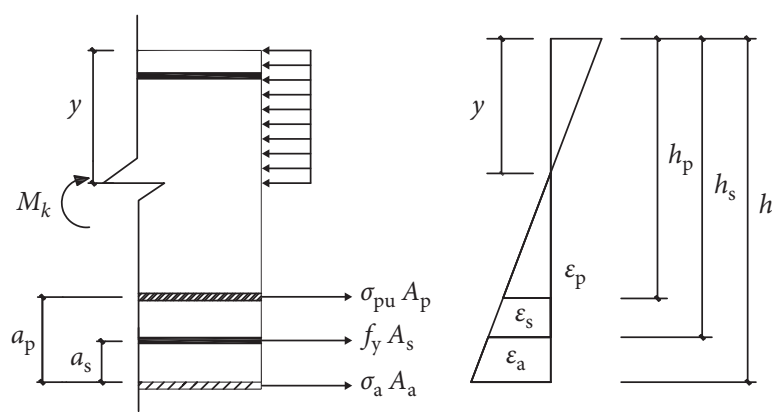

FIGURE 14: Internal force of the midspan section in the limit state.

The following expression was then obtained:

$x=\left(\beta_{s}+\beta_{p}+\beta_{a}-\beta_{s}^{\prime}\right) h_{p}+\frac{\Delta \sigma_{p u} A_{p}}{f_{c} b}=\beta_{0} h_{p}+\frac{\Delta \sigma_{p u} A_{p}}{f_{c} b}$.
According to Figure 14, the equation can be expressed as follows:

$M=f_{y} A_{s}\left(h_{s}-0.5 x\right)+\left(\sigma_{p e}+\Delta \sigma_{p u}\right) A_{p}\left(h_{p}-0.5 x\right)+\sigma_{a} A_{a}(h-0.5 x)+f_{y}^{\prime} A_{s}^{\prime}\left(0.5 x-a_{s}^{\prime}\right)$.

Consequently,

$x=\frac{2\left[M-f_{y} A_{s} h_{s}-\left(\sigma_{p e}+\Delta \sigma_{p u}\right) A_{p} h_{p}-\sigma_{a} A_{a} h+f_{y}^{\prime} A_{s}^{\prime} a_{s}^{\prime}\right]}{f_{y}^{\prime} A_{s}^{\prime}-f_{y} A_{s}-\left(\sigma_{p e}+\Delta \sigma_{p u}\right) A_{p}-\sigma_{a} A_{a}}$.

Substituting equation (7) into equation (9), the stress increment of unbonded tendons $\Delta \sigma_{\mathrm{pu}}$ in the limiting state was determined. Given that $h_{\mathrm{s}}=h_{\mathrm{p}}$ at the midspan, which was approximately $0.08 h_{\mathrm{p}}$, the influence of $\beta_{\mathrm{s}}^{\prime}$ was negligible. Therefore, the equation can be simplified as follows:

$$
\Delta \sigma_{p u}=\left(\frac{1}{\beta_{p}} \sqrt{1-\frac{2 M}{f_{c} b h_{p}^{2}}+\frac{\beta_{a}}{10 h_{p}}}+\frac{1-\beta_{0}}{\beta_{p}}\right) \sigma_{p e}
$$

where $\beta_{\mathrm{p}}$ and $\beta_{0}$ are independent variables, and $\sqrt{1-\left(2 M / f_{c} b h_{p}^{2}\right)+\left(\beta_{a} / 10 h_{p}\right)}$ has the compressive strength of the concrete and the reinforcement index of AA plate as parameters. Hence, suitable parameters $\eta_{1}$ and $\eta_{2}$ were required for substitution.

$$
\Delta \sigma_{p u}=\left(\eta_{1} \frac{1}{\beta_{p}}+\frac{1-\beta_{0}}{\beta_{p}}+\eta_{2}\right) \sigma_{p e} .
$$




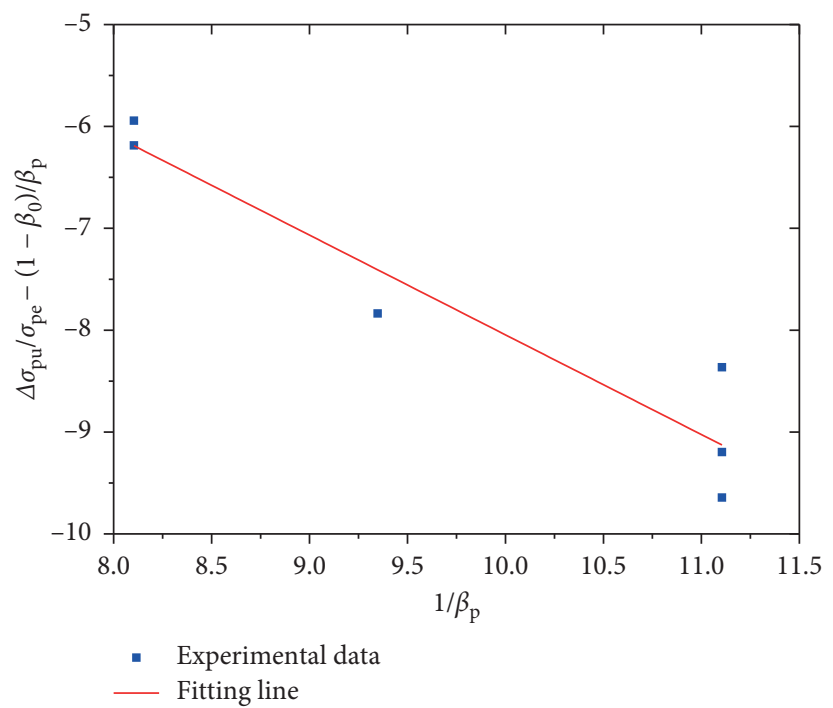

FIGURE 15: Fitting curves of parameters $\eta_{1}$ and $\eta_{2}$.

The above equation can be rewritten as follows:

$$
\frac{\Delta \sigma_{p u}}{\sigma_{p e}}-\frac{1-\beta_{0}}{\beta_{p}}=\eta_{1} \frac{1}{\beta_{p}}+\eta_{2} .
$$

The experimental data were fitted, thus resulting in $\eta_{1}=-0.9788$ and $\eta_{2}=1.7416$, with a correlation coefficient of 0.9063, as shown in Figure 15.

Substituting $\eta_{1}$ and $\eta_{2}$ into equation (10), the stress increment of the unbonded tendons was obtained as follows:

$$
\Delta \sigma_{p u}=\left(-\frac{0.9788}{\beta_{p}}+\frac{1-\beta_{0}}{\beta_{p}}+1.7416\right) \sigma_{p e} .
$$

The equation of the ultimate stress of the unbonded tendons of the UPC beam strengthened with the AA plate can then be expressed as follows:

$$
\sigma_{p u}=\left(2.7416-\frac{0.9788}{\beta_{p}}+\frac{1-\beta_{0}}{\beta_{p}}\right) \sigma_{p e} .
$$

4.2. Flexure Strength. Bending and shear failures may occur in UPC beams under the ultimate flexural strength. In this study, all the six beams were subjected to bending failure, and they conformed to the failure mode of ideally reinforced beams. According to Figure 14, the equilibrium equation can be expressed as follows:

$$
f_{c} b x=f_{y} A_{s}+\left(\sigma_{p e}+\Delta \sigma_{p u}\right) A_{p}+\sigma_{a} A_{a}-f_{y}^{\prime} A_{s}^{\prime} .
$$

The height of the compression zone $x$ can be obtained by the following transformation:

$$
x=\frac{f_{y} A_{s}+\left(\sigma_{p e}+\Delta \sigma_{p u}\right) A_{p}+\sigma_{a} A_{a}-f_{y}^{\prime} A_{s}^{\prime}}{f_{c} b} .
$$

For equilibrium, the ultimate flexural strength can be expressed as follows:
$M_{u}=\alpha f_{c} b x\left(h_{0}-0.5 x\right)+f_{y}^{\prime} A_{s}^{\prime}\left(h_{0}-a_{s}^{\prime}\right)+f_{a} A_{a}\left(a_{s}+0.5 t_{a}\right)$,

where $a_{\mathrm{s}}=a_{\mathrm{p}}$ in the middle span. The flexural strengths of the UPC beams strengthened with AA plates can be determined based on equations (11)-(15). A comparison of the flexural capacities before and after strengthening is shown in Table 5. The flexural strength was improved after the beam was strengthened with AA plates.

As can be seen from Table 5, the flexural strength of all the other five beams increased, with the exception of AL1. In particular, the average increase ratio was $14 \%$, and the increase ratio of each beam was proportional to the reinforcement ratio of the non-prestressed reinforcement. Improper construction during the replacement of the damaged concrete may be the main limitation to the improvement of the flexural capacity of the AL1 beam. Therefore, it can be concluded that the strengthening technique using the AA plates can effectively improve the flexural capacity of UPC beams.

4.3. Ductility. In this study, the coefficient of displacement ductility was used as an index for the investigation of the ductility of the strengthened beams. To compare the displacement ductility before and after strengthening, the displacement ductility coefficients were compared with those of the strengthened beams at the initial damage stage, as shown in Table 6 . In particular, the displacement ductility factor $m$ is the ratio of the yielding deflection of the midspan $\Delta u$, which is the ratio of the deflection upon the yielding of the non-prestressed reinforcements to the ultimate deflection of the midspan $\Delta y$.

Based on a comparison of the data before and after strengthening, the yielding deflection $\Delta u$, ultimate deflection of the midspan $\Delta y$, and displacement ductility factor of the specimens decreased. The average decrease ratio of the displacement ductility factor was $34.14 \%$. Regularity was 
TABLE 5: Error of the equation and increase of the flexural strength.

\begin{tabular}{lcccc}
\hline No. & Calculated value of $m_{\mathrm{u}}(\mathrm{MPa})$ & Experimental value of $m_{\mathrm{u}}(\mathrm{MPa})$ & Error $(\%)$ & Degree of bearing capacity increase $(\%)$ \\
\hline AL1 & 164.65 & 165.89 & -0.75 & -7.84 \\
AL2 & 206.74 & 212.80 & -2.93 & 4.31 \\
AL3 & 279.84 & 247.55 & 11.54 & 23.78 \\
AS1 & 107.46 & 102.55 & 4.57 & 22.08 \\
AS2 & 146.88 & 135.31 & 7.88 & 30.11 \\
AS3 & 161.64 & 135.94 & 15.90 & 15.20 \\
\hline
\end{tabular}

TABLE 6: Comparison of displacement ductility of specimens.

\begin{tabular}{cccccccc}
\hline \multirow{3}{*}{ No. } & \multicolumn{3}{c}{ After strengthening } & \multicolumn{3}{c}{ First failure } \\
& $\beta_{0}$ & $\Delta u(\mathrm{~mm})$ & $\Delta y(\mathrm{~mm})$ & $\mu$ & $\Delta u(\mathrm{~mm})$ & $\Delta y(\mathrm{~mm})$ & $\mu^{\prime}$ \\
\hline AL1 & 0.13 & 83 & 139 & 1.67 & 24 & 141 & 5.88 \\
AL2 & 0.17 & 52 & 90 & 1.73 & 46 & 141 & 3.07 \\
AL3 & 0.24 & 39 & 67 & 1.72 & 46 & 86 & 1.87 \\
AS1 & 0.16 & 87 & 106 & 1.22 & 43 & 154 & 3.58 \\
AS2 & 0.23 & 74 & 120 & 1.62 & 64 & 116 & 1.81 \\
AS3 & 0.26 & 70 & 90 & 1.29 & 53 & 72 & 1.36 \\
\hline
\end{tabular}

observed between the coefficient of displacement ductility and the comprehensive reinforcement index of the beams before strengthening; however, such regularity was not observed after strengthening, which can be attributed to the displacement of the damaged concrete by the beam and the variations in stress of the unbonded prestressed reinforcement and non-prestressed reinforcement. Moreover, further research is required for clarification.

\section{Conclusion}

The aim of this study was the prediction of the flexural behaviour of UPC beams strengthened using an AA plate based on a series of tests conducted on the strengthened UPC beams. The conclusions can be summarized as follows:

(1) AA plate bonded by MPC improved the flexural capacity and decreased the ductility of the UPC beams. The flexural strength and displacement ductility factor of the six specimens increased and decreased by an average of $14 \%$ and $34.14 \%$, respectively.

(2) The use of MPC in the bonding of the AA plate for beam strengthening resulted in minimal slippage, which did not impact the full utilization of the strength of the AA plate.

(3) The constitutive AA5083 relationship model was presented, which can serve as a basis for further research.

(4) The flexural strengths of the UPC beams strengthened with the AA plate bonded by MPC were characterized based on the equation for the stress increment of unbonded tendons in the limiting state, which involved the reinforcement index of prestressed tendons and comprehensive reinforcement index.

(5) The result of this investigation validates the viability of using AA plates as an alternative to the prevailing
FRP laminates and steel plates as externally bonded flexural strengthening material.

(6) Further experimental studies will be required to confirm the effectiveness of using bonded AA plates in corrosive environment.

\section{Data Availability}

The raw/processed data required to reproduce these findings cannot be shared at this time as the data also form part of an ongoing study.

\section{Disclosure}

The funders had no role in the design of the study; in the collection, analyses, or interpretation of data; in the writing of the manuscript, or in the decision to publish the results.

\section{Conflicts of Interest}

The authors declare no conflicts of interest.

\section{Acknowledgments}

The authors specially thank Xing Zhao, Xiangri Geng, Xinyu Cong for their efforts in experiment. This research was supported by the National Natural Science Foundation of China (NSFC) under Grant no. 51778186.

\section{References}

[1] M. C. Sundarraja and S. Rajamohan, "Strengthening of RC beams in shear using GFRP inclined strips-an experimental study," Construction and Building Materials, vol. 23, no. 2, pp. 856-864, 2009.

[2] R. A. Hawileh, H. A. Rasheed, J. A. Abdalla, and A. K. AlTamimi, "Behavior of reinforced concrete beams strengthened with externally bonded hybrid fiber reinforced polymer systems," Materials \& Design, vol. 53, pp. 972-982, 2014.

[3] L. Huang, B. Yan, L. Yan, Q. Xu, H. Tan, and B. Kasal, "Reinforced concrete beams strengthened with externally bonded natural flax FRP plates," Composites Part B: Engineering, vol. 91, pp. 569-578, 2016.

[4] S. Aykac, I. Kalkan, B. Aykac, S. Karahan, and S. Kayar, "Strengthening and repair of reinforced concrete beams using external steel plates," Journal of Structural Engineering, vol. 139, no. 6, pp. 929-939, 2013.

[5] M. Z. Naser, R. A. Hawileh, and J. A. Abdalla, "Fiber-reinforced polymer composites in strengthening reinforced concrete structures: a critical review," Engineering Structures, vol. 198, Article ID 109542, 2019. 
[6] H. A. Rasheed, J. Abdalla, R. Hawileh, and A. K. Al-Tamimi, "Flexural behavior of reinforced concrete beams strengthened with externally bonded Aluminum Alloy plates," Engineering Structures, vol. 147, pp. 473-485, 2017.

[7] J. H. Zhu, M. C. Zhu, L. L. Wei, W. W. Li, and F. Xing, "Bond behavior of aluminum laminates in NSM technique," Applied Mechanics and Materials, vol. 501-504, pp. 1053-1060, 2014.

[8] J. A. Abdalla, F. H. Hraib, R. A. Hawileh, and A. M. Mirghani, "Experimental investigation of bond-slip behavior of aluminum plates adhesively bonded to concrete," Journal of Adhesion Science and Technology, vol. 31, no. 1, pp. 82-99, 2016.

[9] J. H. Zhu, L. L. Wei, W. T. Wu, F. Xing, and R. Feng, "Experimental study of concrete strengthened by stiffened aluminum plate," Applied Mechanics and Materials, vol. 584-586, pp. 997-1000, 2014.

[10] J. Zhu, L. Wei, M. Zhu, W. Li, and X. Feng, "Experimental study of bond behavior on aluminum alloy plate-to-concrete interface," Applied Mechanics and Materials, vol. 501-504, pp. 805-810, 2014.

[11] J. A. Abdalla, A. S. Abu-Obeidah, R. A. Hawileh, and H. A. Rasheed, "Shear strengthening of reinforced concrete beams using externally-bonded aluminum alloy plates: an experimental study," Construction and Building Materials, vol. 128, pp. 24-37, 2016.

[12] A. Abu-Obeidah, R. A. Hawileh, and J. A. Abdalla, "Finite element analysis of strengthened RC beams in shear with aluminum plates," Computers \& Structures, vol. 147, pp. 3646, 2015.

[13] A.-j. Wang, N. Song, X.-j. Fan et al., "Characterization of magnesium phosphate cement fabricated using pre-reacted magnesium oxide," Journal of Alloys and Compounds, vol. 696, pp. 560-565, 2017.

[14] H. Ma and B. Xu, "Potential to design magnesium potassium phosphate cement paste based on an optimal magnesia-tophosphate ratio," Materials \& Design, vol. 118, pp. 81-88, 2017.

[15] H. Chang and W. Zhou, "Experiment on bond behavior of aluminum alloy bonded to concrete by inorganic adhesive," Journal of Harbin Institute of Technology, vol. 51, pp. 58-63, 2019. 